\title{
Blood purification therapies in methotrexate-induced acute kidney injury: four case reports
}

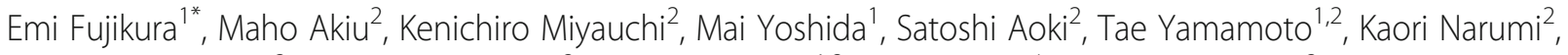
Noriko Yanagisawa ${ }^{3}$, Takashi Nakamichi ${ }^{2}$, Mariko Miyazaki ${ }^{1,2}$, Hiroshi Sato ${ }^{4}$ and Sadayoshi Ito $^{2}$

\begin{abstract}
Background: Methotrexate (MTX), a folic acid antimetabolite, is administered at a high dose for the treatment of diseases such as leukemia and malignant lymphoma. Often, an effort is made to reduce the adverse effects of MTX by monitoring MTX concentration in the blood and administering a high dose of leucovorin. However, side effects of MTX are still reported. MTX is metabolized in the liver and eliminated via the kidneys; hence, blood purification therapy is useful for the reduction of MTX blood concentration in case of renal impairment.

Case presentation: We performed various types of blood purification therapies in four cases of MTX poisoning that accompanied renal impairment.

Conclusions: Based on our results, we concluded that hemodialysis or hemoperfusion with an activated carbon absorption column was useful for the elimination of MTX from the blood. It is important to choose an appropriate blood purification method understanding the characteristics of each blood purification method.
\end{abstract}

Keywords: High-dose methotrexate, Acute kidney injury, Blood purification therapy, Reduction rates

\section{Background}

Methotrexate (MTX), a folic acid antimetabolite, is used for the treatment of various diseases, including rheumatoid arthritis and blood diseases such as leukemia and malignant lymphoma. When the concentration of MTX exceeds the prescribed safe limit, the drug affects normal cells; the reported side effects include bone marrow suppression, impairment of renal and liver function, and mucous membrane disorders.

MTX and its metabolite, 7-hydroxy-MTX, dissolve poorly in urine. Furthermore, in acidic conditions, crystals precipitate inside the lumen of renal tubules and cause renal impairment. The compounds have also been indicated to directly impair renal tubular cells. When MTX is administered at high doses, the use of methods, such as sufficient fluid replacement, alkalization of urine, and administration of the folic acid preparation leucovorin

\footnotetext{
* Correspondence: emifujikura@med.tohoku.ac.jp

${ }^{1}$ Department of Blood Purification, Tohoku University Hospital, 1-1

Seiryomachi, Aoba-ku, Sendai, Miyagi 980-8574, Japan

Full list of author information is available at the end of the article
}

(LV), prevents the adverse effects that arise from delayed reduction.

Since the 1970s, there have been many reports into the prediction and prevention of adverse effects by monitoring the blood concentrations of medicines [1, 2]. Recently, with the introduction of therapeutic drug monitoring (TDM), it has become possible to reduce the side effects of MTX by managing its pharmacokinetics. The risk values for the blood concentration of MTX are $\geq 10, \geq 1$, and $\geq 0.1 \mu \mathrm{mol} / \mathrm{L}$ at 24,48 , and $72 \mathrm{~h}$ after administration [3].

There have been several reports [4-16] of blood purification methods for the treatment of MTX poisoning, such as hemodialysis (HD), hemodialysis filtration (HDF), and hemoperfusion (HP) using an activated carbon absorption column. However, currently, no method has been universally established thus far.

We performed blood purification therapy in four cases that presented with abnormal elevation of MTX blood concentration after treatment with high-dose MTX that 
led patients to acute renal impairment. We compared the results of the various blood purification methods.

\section{Case presentation}

Case 1: male, 36-year-old patient

The patient was administered $5.8 \mathrm{~g} /$ day of MTX for the treatment of malignant lymphoma relapse in the central nervous system. Prior to this treatment, the serum creatinine $(\mathrm{sCr})$ level of the patient was $0.8 \mathrm{mg} / \mathrm{dL}$. When the blood concentration of MTX reached $31.0 \mu \mathrm{mol} / \mathrm{L}$ and the $\mathrm{sCr}$ reached $3.2 \mathrm{mg} / \mathrm{dL}$, we performed $\mathrm{HD}$ three times and subsequently performed HDF five times. Blood purification therapy was provided daily, and the total duration of blood purification was 8 days. After final blood purification therapy, the blood concentration of MTX was $0.36 \mu \mathrm{mol} / \mathrm{L}$. The blood concentration of MTX decreased to the target value $(<0.1 \mu \mathrm{mol} / \mathrm{L})$ in 18 days. Renal function recovered slowly; approximately 40 days was required for the normalization of $\mathrm{sCr}$.

\section{Case 2: male, 45-year-old patient}

The patient received chemotherapy in accordance with the "Japan Adult Leukemia Study Group's Acute Lymphoblastic Leukemia (JALSG ALL) 202 protocol" for the treatment of acute lymphatic leukemia. For the consolidation treatment, the patient was administered $4.6 \mathrm{~g}$ /day of MTX. Prior to the administration of MTX, the sCr level was $0.7 \mathrm{mg} / \mathrm{dL}$. When the MTX blood concentration was $23.0 \mu \mathrm{mol} / \mathrm{L}$ and the $\mathrm{sCr}$ level was $1.8 \mathrm{mg} / \mathrm{dL}$, HP was performed nine times using an activated carbon absorption column. Blood purification therapy was provided daily, and the total blood purification duration was 9 days. After final blood purification therapy, the blood concentration of MTX was $0.14 \mu \mathrm{mol} / \mathrm{L}$. Renal function recovered slowly; 14 days was required to decrease the concentration of MTX in the blood to the target value, and approximately 30 days were required for the normalization of $\mathrm{sCr}$.

\section{Case 3: male, 16-year-old patient}

The patient received chemotherapy in accordance with the JALSG ALL T11 for the treatment of acute lymphatic leukemia. MTX (9.8 g/day) was administered as a consolidation treatment, and prior to the treatment, the $\mathrm{sCr}$ level was $0.6 \mathrm{mg} / \mathrm{dL}$. When the MTX blood concentration reached $64.8 \mu \mathrm{mol} / \mathrm{L}$ and the $\mathrm{sCr}$ level was $3.63 \mathrm{mg} / \mathrm{dL}$, we performed HD and HP combination therapy three times. Initially, two sessions of blood purification therapy were provided daily and the third treatment was commenced 4 days later. In principle, blood purification therapy should be performed daily until the concentration of MTX reached near the target value (under $0.1 \mu \mathrm{mol} / \mathrm{L}$ ). Nevertheless, in this case, the attending pediatrician insisted that the frequency of the blood purification therapy should be minimized as much as possible due to burdens of the treatment. The total duration of blood purification was 6 days. After final blood purification therapy, the blood concentration of MTX was $0.862 \mu \mathrm{mol} / \mathrm{L}$. The blood concentration of MTX decreased to the target value in 20 days, and approximately 50 days were required for the $\mathrm{sCr}$ level to normalize.

\section{Case 4: female, 72-year-old patient}

The patient was administered $13.6 \mathrm{~g}$ of MTX for the treatment of metastasis of lung osteosarcoma. Prior to this treatment, the $\mathrm{sCr}$ level was $0.56 \mathrm{mg} / \mathrm{dL}$. When the MTX blood concentration reached $183.6 \mu \mathrm{mol} / \mathrm{L}$ and the $\mathrm{sCr}$ level was at $4.23 \mathrm{mg} / \mathrm{dL}$, we performed both HD and HP once, before the patient was transferred to another facility. The blood concentration of MTX after blood purification therapy was $67.6 \mu \mathrm{mol} / \mathrm{L}$. In addition, liver impairment occurred from the second day of MTX administration; however, on the following day, a tendency toward improvement was observed in response to the administration of a glycyrrhizin preparation. Her renal function eventually recovered completely 8 months later.

In all patients, we used the double-lumen catheters for blood access and heparin sodium for anticoagulation. Dialysate flow rates in HD were $500 \mathrm{~mL} / \mathrm{min}$ in all sessions. In HDF, we adopted post-dilution mode. Dialysate flow rate was $2000 \mathrm{~mL} / \mathrm{h}$. In HD + HP, the connection of HD and HP was in series and the carbon adsorption column was connected before the dialyzer.

The cases are summarized in Table 1.

We show conditions such as the type of blood purification therapy and the average reduction rates in Table 2 and Fig. 1. Prior to blood purification therapy, renal function and MTX concentration were different in each case; therefore, a simple comparison was difficult. However, we compared the average effect of each type of blood purification therapy. The average reduction rates of HD alone, HP alone, and both HP and HD (HP + HD) were approximately equal or better than those of HDF (Fig. 1). In case 1, blood concentration of MTX decreased after HD but HDF was subsequently performed. HDF was performed to enhance the elimination of MTX; however, it was unclear whether HDF was more effective than HD.

In cases $1-3$, we observed the progress until renal function normalized. These observations are summarized in Table 3. In all three cases, the renal function recovered to the level prior to MTX administration. We hypothesized that the time required for the blood concentration of MTX to decrease to the target value and for the renal function to recover was dependent on the MTX concentration prior to the blood purification therapy. 
Table 1 Cases

\begin{tabular}{|c|c|c|c|c|}
\hline & Primary disease & $\begin{array}{l}\text { Dose of MTX (g) per day } \\
\text { (per body surface area) }\end{array}$ & $\begin{array}{l}\text { eGFR prior to administration [mL/ } \\
\left.\mathrm{min} / 1.73 \mathrm{~m}^{2}\right] \text {, serum } C r e[\mathrm{mg} / \mathrm{dL}]\end{array}$ & $\begin{array}{l}\text { MTX maximum blood } \\
\text { concentration }[\mu \mathrm{mol} / \mathrm{L}]\end{array}$ \\
\hline Case 1 , age 36 years, male & $\begin{array}{l}\text { Diffuse large B cell lymphoma, } \\
\text { central nervous system } \\
\text { reoccurrence }\end{array}$ & $5.8 \mathrm{~g} /$ day $\left(3.5 \mathrm{~g} / \mathrm{m}^{2}\right)$ & eGFR 88.5 , Cre 0.8 & $\begin{array}{l}\text { MTX blood } \\
\text { concentration } 31.0\end{array}$ \\
\hline Case 2 , age 45 years, male & Acute lymphatic leukemia & $4.6 \mathrm{~g} /$ day $\left(3.0 \mathrm{~g} / \mathrm{m}^{2}\right)$ & eGFR 96.1, Cre 0.7 & $\begin{array}{l}\text { MTX blood } \\
\text { concentration } 23.0\end{array}$ \\
\hline Case 3 , age 16 years, male & Acute lymphatic leukemia & $9.8 \mathrm{~g} /$ day $\left(5.0 \mathrm{~g} / \mathrm{m}^{2}\right)$ & eGFR 178.8, Cre 0.49 & $\begin{array}{l}\text { MTX blood } \\
\text { concentration } 138.8\end{array}$ \\
\hline Case 4 , age 75 years, female & $\begin{array}{l}\text { Osteosarcoma, metastasis } \\
\text { to both lungs }\end{array}$ & $13.6 \mathrm{~g} /$ day $\left(8.6 \mathrm{~g} / \mathrm{m}^{2}\right)$ & eGFR 81.5, Cre 0.54 & $\begin{array}{l}\text { MTX blood } \\
\text { concentration } 442.0\end{array}$ \\
\hline
\end{tabular}

MTX methotrexate, eGFR estimated glomerular filtration rate, Cre creatinine

\section{Discussion}

The administration of high-dose MTX causes serious adverse effects including immediate shock after administration, renal function impairment, liver function impairment, and acute respiratory failure in the early stage. Furthermore, when there is a delayed elimination of at least $72 \mathrm{~h}$, fatal side effects have been reported, such as bone marrow suppression, digestive tract hemorrhage, and central nervous system impairment. It has been reported that approximately $80 \%$ of the fatal cases resulted from bone marrow suppression [17].

In a typical case of MTX-induced renal impairment, urine output was unaffected; in most cases, the impairment was reversible. The $\mathrm{sCr}$ values reached a peak within 1 week and returned to their previous values between 1 and 3 weeks [18].

To prevent adverse effects, the blood concentration is monitored and preventive measures are taken if the risk limit is reached at $72 \mathrm{~h}$ after administration. These measures include increasing the dose of $\mathrm{LV}$, in order to minimize the damage to normal cells, until MTX blood concentration decreases below $0.1 \mu \mathrm{mol} / \mathrm{L}$, as given in the interview form [3].

For all cases, we ensured sufficient fluid replacement and performed urine alkalization, which are the standard treatments for high-dose MTX, but still observed an elevation in MTX blood concentration; this effect has been previously reported. Many studies have investigated genetic polymorphism with regard to the metabolism and elimination of MTX, and it was reported that a single-nucleotide polymorphism (SNP) of methylenetetrahydrofolate reductase (MTHFR), which is involved in the metabolism of MTX, contributed to the effectiveness and toxicity of MTX [19-22].

If the in vitro extracellular MTX concentration is high, the movement of LV into the cell is inhibited; therefore, when the MTX concentration exceeds $100 \mu \mathrm{M}$, the effect of LV is inhibited [23]. If the blood concentration does not decrease below the risk value at 48 or $72 \mathrm{~h}$ after MTX administration, or if it is predicted that it will not, then MTX should be eliminated by blood purification therapy.

At present, the reported blood purification therapies for the treatment of MTX poisoning include HD, HDF, and HP using an activated carbon absorption column, continuous hemofiltration (CHF), and plasma exchange [4-15].

MTX is a small molecule with a molecular weight of $454 \mathrm{Da}$. The protein binding rate is $50 \%$, and the distribution volume is relatively low $(0.5-1.0 \mathrm{~L} / \mathrm{kg})$. Owing to these characteristics, cytotoxic-free MTX can be eliminated with relative ease by using HD. It was reported that MTX has a high intracellular distribution, and hence, blood concentration immediately increased again after dialysis; frequent blood purification therapy was necessary $[7,8,24]$. Similar effects were observed in our studies; the MTX blood concentration increased again on the day following dialysis.

Table 2 Comparison of various types of blood purification methods

\begin{tabular}{|c|c|c|c|}
\hline & Column used & Other conditions & Average reduction rate ${ }^{a}$ \\
\hline HD & PES-15Sa ${ }^{\oplus}$ & QB 150 mL/min, $4 \mathrm{~h}$ & $58.3 \pm 6.17 \%$ \\
\hline HDF & PES-15Sa & $\begin{array}{l}\text { QB } 200 \mathrm{~mL} / \mathrm{min}, 4 \mathrm{~h}, \\
\text { (Sublood }^{-B S G} 8 \mathrm{~L} / 4 \text { h) }\end{array}$ & $40.0 \pm 5.63 \%$ \\
\hline $\mathrm{HP}$ & CHS-350 & QB 150 mL/min, $4 \mathrm{~h}$ & $55.3 \pm 11.6 \%$ \\
\hline $\mathrm{HD}+\mathrm{HP}$ & $\begin{array}{l}\text { VPS-13HA } / \text { /PES-13Sa } \\
\text { (absorption column CHS-350 }{ }^{\circledast}\end{array}$ & QB 80-180 mL/min, $4 \mathrm{~h}$ & $57.9 \pm 10.6 \%$ \\
\hline
\end{tabular}

$H D$ hemodialysis, $H D F$ hemodialysis filtration, $H P$ hemoperfusion, $Q B$ quantity of blood flow. $P E S-15 S a^{\oplus}$ and $P E S-13 S a^{\oplus}$ polyethersulfone dialyzer, $V P S-13 H A^{\oplus}$ vitamin E-coated polysulfone dialyzer, Hemosorba $\mathrm{CHS}-350^{\circledR}$ activated chacol column, Sublood ${ }^{\oplus}-\mathrm{BSG}$ substitution fluid

${ }^{a}$ Reduction rate is calculated by dividing the difference of MTX blood concentration before and after blood purification by MTX blood concentration before blood purification 


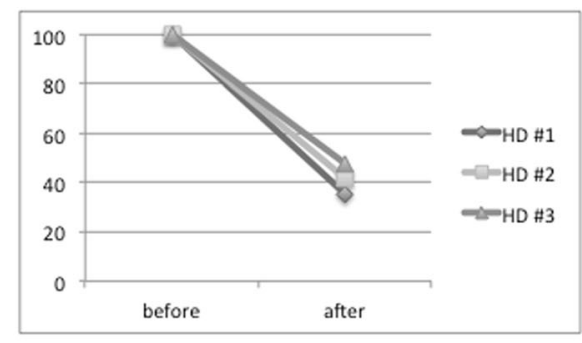

$<\mathrm{HD}>$ Average reduction rate $\quad 58.3 \pm 6.17 \%$

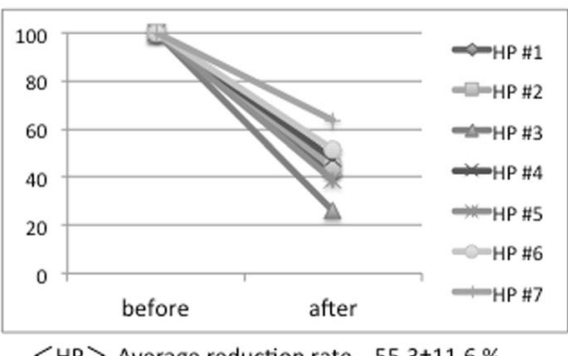

$<\mathrm{HP}\rangle$ Average reduction rate $55.3 \pm 11.6 \%$
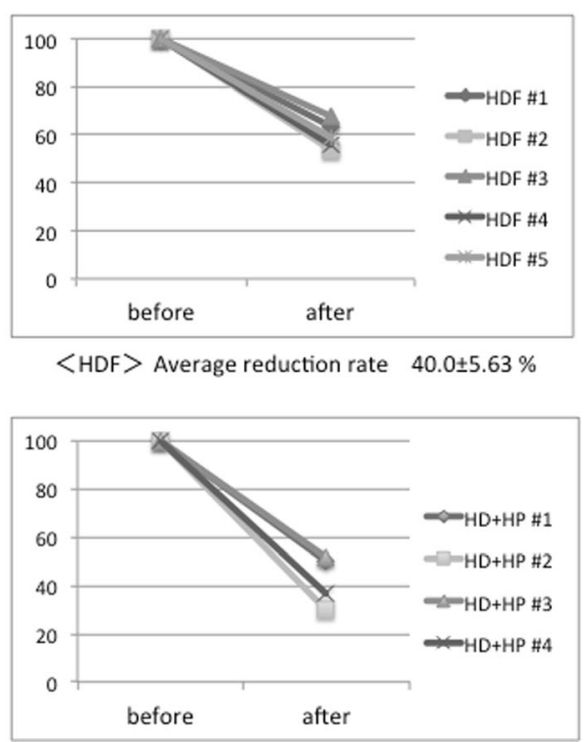

$<\mathrm{HD}+\mathrm{HP} \ddagger>$ Average reduction rate $57.9 \pm 10.6 \%$

Fig. 1 Comparison of reduction rates in the various blood purification methods. Reduction rate is calculated by dividing the difference of MTX blood concentration before and after blood purification by MTX blood concentration before blood purification. HD + HP therapy \#1-\#3 was done in case $3 ; \mathrm{HD}+\mathrm{HP}$ therapy \#4 was done in case 4

In a previous study, CHF after HP with activated carbon was performed in order to prevent the blood concentration from increasing again [16]. When HF is performed continuously, the drug that has moved into the third space is eliminated, and a rebound in the MTX levels after the completion of blood purification therapy may be suppressed. However, as LV is also eliminated in this process, one drawback is the requirement for a high dose of LV. HP, which uses an activated carbon absorption membrane, can eliminate substances with a molecular weight between 100 and $10,000 \mathrm{Da}$; hence, it is extremely effective for the treatment of toxicosis. When MTX is bound to a protein, or present at a low blood concentration, it can also be eliminated efficiently. HP does not require dialysis fluid or related equipment and is relatively simple to perform. When the patient shows concurrent symptoms such as hematopenia, the process may be performed in a single room in a hospital ward. However, the adhesion of sucrose, heparin, and platelets to the activated carbon can be problematic.

Plasma exchange can eliminate substances bound to protein, but HP has been shown to be more efficient than plasma exchange [5, 7]. Plasma exchange requires a large amount of replacement plasma, which increases the cost and the probability of infection. However, for patients with liver function impairment, plasma exchange may still be indicated.

The relative merits of HDF and HD with regard to MTX reduction rate are still undetermined. We performed $\mathrm{HDF}$ after $\mathrm{HD}$ in case 1, but the reduction rate

Table 3 Summary of the progress of the cases

\begin{tabular}{|c|c|c|c|c|c|c|c|}
\hline & \multicolumn{2}{|c|}{$\begin{array}{l}\text { Data before the start } \\
\text { of blood purification }\end{array}$} & \multirow[t]{2}{*}{$\begin{array}{l}\text { Blood purification } \\
\text { method }\end{array}$} & \multirow[t]{2}{*}{ Column used } & \multirow[t]{2}{*}{$\begin{array}{l}\text { Average } \\
\text { reduction rate }\end{array}$} & \multirow{2}{*}{$\begin{array}{l}\text { Days required } \\
\text { for } \mathrm{MTX} \text { to reach } \\
0.1 \mu \mathrm{mol} / \mathrm{L}\end{array}$} & \multirow{2}{*}{$\begin{array}{l}\text { Days required for } \\
\text { serum Cre to decrease } \\
\text { to its previous value }\end{array}$} \\
\hline & $\begin{array}{l}\text { MTX } \\
(\mu \mathrm{mol} / \mathrm{L})\end{array}$ & $\begin{array}{l}\text { Serum Cre } \\
(\mathrm{mg} / \mathrm{dL})\end{array}$ & & & & & \\
\hline Case 1 & 31.0 & 3.20 & $\mathrm{HD} \rightarrow \mathrm{HDF}$ & PES-15Sa & HD $58.3 \pm 6.17 \%$ HDF $40.0 \pm 5.63 \%$ & 18 days & 40 days \\
\hline Case 2 & 23.0 & 1.80 & $\mathrm{HP}$ & CHS-350 & $55.3 \pm 11.6 \%$ & 14 days & 18 days \\
\hline Case 3 & 62.4 & 3.75 & $\mathrm{HD}+\mathrm{HP}$ & $\begin{array}{l}\text { VPS-13HA }{ }^{\oplus} / \text { PES-13Sa } \\
\text { (absorption column CHS-350 }\end{array}$ & $56.1 \pm 12.2 \%$ & 20 days & $\begin{array}{l}\text { Approximately } \\
50 \text { days }\end{array}$ \\
\hline Case 4 & 183.6 & 4.23 & $\mathrm{HD}+\mathrm{HP}$ & $\begin{array}{l}\text { VPS-13HA }{ }^{\oplus} \text { (absorption } \\
\text { column CHS-350 }\end{array}$ & $63.2 \%$ & - & - \\
\hline
\end{tabular}

MTX methotrexate, eGFR estimated glomerular filtration rate, $C r e$ creatinine, $H D$ hemodialysis, $H D F$ hemodialysis filtration, $H P$ hemoperfusion. $P E S-15 S a^{\circledR}$ and PES-13Sa ${ }^{\circledast}$ polyethersulfone dialyzer, VPS-13HA ${ }^{\oplus}$ vitamin E-coated polysulfone dialyzer, Hemosorba CHS-350 ${ }^{\oplus}$ activated chacol column, Sublood ${ }^{\oplus}-$ BSG substitution fluid

${ }^{a}$ Reduction rate is calculated by dividing the difference of MTX blood concentration before and after blood purification by MTX blood concentration before blood purification 
was lower than that with HD alone. The dialysis efficiency may not always be higher with peritoneal dialysis; in particular, for small molecules such as MTX, the efficiency is lower than that of blood dialysis.

Widemann et al. compared the efficiency of blood purification methods in renal failure following high-dose MTX administration based on the reports published between 1980 and 2002 [25]. MTX elimination was low after peritoneal dialysis and plasma exchange, and the highest reduction rate (78\%) was found after HP + HD treatment. Analysis of the individual methods revealed that the highest reduction rate for HD using a high-flux membrane was $75.5 \%$, and 50 and $53 \%$ for HD alone and HP alone, respectively.

A combined treatment with HD and HP would theoretically produce excellent elimination, as it would remove both free and protein-bound MTX. These treatments are also useful for electrolyte and acid-base equilibrium abnormalities resulting from acute renal impairment. There are several reports that show that the combination of HD and HP was the most effective treatment $[6,8,10,13]$. This therapy is useful for not only the removal of MTX but also the renal support. In cases 3 and 4, the renal dysfunction was severe and the serum concentration of MTX was very high, so we chose HD + $\mathrm{HP}$ in order to decrease the concentration as soon as possible. Our experience revealed the efficacy of HD + HP therapy in patients with both severe renal dysfunction and higher MTX blood levels.

It has recently been found that carboxypeptidase- $\mathrm{G}_{2}$ $\left(\mathrm{CPDG}_{2}\right)$ rapidly hydrolyzed MTX into inactive metabolites and reduced the blood concentration by one or two orders of magnitude within a few minutes; therefore, it is useful for the treatment of renal impairment after the administration of a high dose of MTX [26]. This drug was approved by the FDA in 2012, and it is currently in the process of clinical trials in Japan. No serious side effects have yet been reported for $\mathrm{CPDG}_{2}$. Contrasting opinions have been reported for the application of $\mathrm{CPDG}_{2}$, but it has been utilized in cases that show high blood concentration, such as $\geq 10 \mu \mathrm{mol} / \mathrm{L}$ at $42 \mathrm{~h}$ after MTX administration. Blood purification therapy involves a risk of hemorrhage from the insertion of the blood access catheter, risk of infection, heparinization resulting from extracorporeal circulation, and secondary hemorrhage arising from platelet reduction, and secondary risks owing to transfusion with a blood preparation. Hence, for this treatment to be established, it must be effective for patients who tend to have hemorrhage as a result of hematopenia or those with a risk of immunosuppression.

As of 2017, $\mathrm{CPDG}_{2}$ is not approved in Japan. There is a continuous need to improve the treatment of kidney injury by determining an administration plan and carefully monitoring the patient after administration. In order to minimize organ damage owing to MTX toxicity, adequate blood purification therapy is important. Under the circumstances, the use of $\mathrm{CPDG}_{2}$ in combination with blood purification therapy is considered to be effective for the reversal of uremia and electrolyte abnormalities caused by kidney injury.

It is important to choose an appropriate blood purification method according to the patient's condition (renal function, compromised immunity, and hemodynamics) and the capabilities and characteristics of the treatment facility, as each blood purification method has both advantages and disadvantages.

\section{Conclusions}

It is important to choose an appropriate blood purification method by understanding the characteristics of each blood purification method. According to our experience, HD and HP combination therapy is clinically useful for MTX poisoning, particularly in patients who developed acute kidney injury due to much higher MTX concentration. It is the merit that MTX removal and renal replacement therapy can be performed at the same time.

However, in the future, the prevention and treatment of MTX poisoning could be improved by administration plans that take into consideration the metabolism and elimination conditions in individual patients and the introduction of the new drug $\mathrm{CPDG}_{2}$. Following the introduction of new drugs, a paradigm shift in treatment may also occur in the future for other types of toxicities. In each case, the applicability of blood purification therapy should be studied.

\section{Abbreviations}

ALL: Acute lymphoblastic leukemia; CHF: Continuous hemofiltration; $\mathrm{CPDG}_{2}$ : Carboxypeptidase-G $\mathrm{G}_{2}$ HD: Hemodialysis; HDF: Hemodialysis filtration; HP: Hemoperfusion; JALSG: Japan Adult Leukemia Study Group; MTHFR: Methylenetetrahydrofolate reductase; MTX: Methotrexate; SCr: Serum creatinine; SNP: Single-nucleotide polymorphism; TDM: Therapeutic drug monitoring

\section{Acknowledgements \\ None. \\ Funding \\ Not applicable. Our manuscript does not contain funding. \\ Availability of data and materials \\ The data and materials were all included in the manuscript. \\ Authors' contributions \\ $E F, M A, K M, M Y, S A, T Y, K N, N Y$, and TN took care of these patients and provided blood purification therapy. EF prepared the manuscript, and MM and $\mathrm{HS}$ revised it critically for important intellectual content. SI organized the comprehensive study project and edited of this manuscript. All authors read and approved the final manuscript.}

Ethics approval and consent to participate

This case report was conducted in compliance with the Declaration of Helsinki. 


\section{Consent for publication}

Written informed consent was obtained from the patients.

\section{Competing interests}

The authors declare that they have no competing interests.

\section{Publisher's Note}

Springer Nature remains neutral with regard to jurisdictional claims in published maps and institutional affiliations.

\section{Author details}

'Department of Blood Purification, Tohoku University Hospital, 1-1 Seiryomachi, Aoba-ku, Sendai, Miyagi 980-8574, Japan. ²Division of Nephrology, Endocrinology and Vascular Medicine, Tohoku University Graduate School of Medicine, Sendai, Miyagi, Japan. ${ }^{3}$ Division of Internal Medicine, Tohoku Kosai Hospital, Sendai, Miyagi, Japan. ${ }^{4}$ Division of Clinical Pharmacology and Therapeutics, Tohoku University Graduate School of Pharmaceutical Sciences, Sendai, Miyagi, Japan.

\section{Received: 28 April 2017 Accepted: 31 August 2017}

Published online: 23 November 2017

\section{References}

1. Stoller RG, Hande KR, Jacobs SA, Rosenberg SA, Chabner BA. Use of plasma pharmacokinetics to predict and prevent methotrexate toxicity. New England J Med. 1977:297:630-4.

2. Isacoff WH, Eilber F, Tabbarah $H$, et al. Phase II clinical trial with high-dose methotrexate therapy and citrovorum factor rescue. Cancer Treat Rep. 1978; 62:1295-304.

3. Pfizer Inc. Methotrexate ${ }^{\oplus}$ fluid for intravenous injection $200 \mathrm{mg}$ pharmaceutical interview form. In Japanese. www.info.pmda.go.jp/go/ interview/2/671450_4222400A1036_2_1F. Accessed 05 Sept 2017.

4. Kono K, Matsumi M, Tokioka H, Nagano O, Iwado S, Hirakawa M. A case of methotrexate-poisoning associated acute renal failure successfully treated with blood purification. J Japan Soc Intensive Care Med. 1996;2:107-11.

5. Bouffet E, Frappaz D, Laville M, Finaz J, Pinkerton CR, Philip T, BrunatMentigny M. Charcoal hemoperfusion and methotrexate toxicity. Lancet 1986;1(8496):1497

6. Relling MV, Stapleton FB, Ochs J, et al. Removal of methotrexate, leucovorin, and their metabolites by combined hemodialysis and hemoperfusion. Cancer. 1988;62:884-8.

7. Tanioka F, Ishihara K, Handa T, Isozaki K, Matsuki A, Oyama T, et al. A case of successful treatment by blood purification for methotrexate poisoning. ICU and CCU. 1989:13:335-9.

8. Hoshi H, Masakane I, Higuchi T, Kato A, Ichiyanagi K, Okuyama Y, et al. A case of methotrexate-induced acute renal failure successfully treated with combined hemoperfusion and hemodialysis. ICU and CCU. 1990;14:1081-7.

9. Mclvor A. Charcoal hemoperfusion and methotrexate toxicity. Nephron. 1991;58(3):378

10. Okada K, Kakuta S, Hidaka S, et al. Attempts to eliminate methotrexate (MTX) by means of extra-corporeal blood purification in MTX-induced acute renal failure. Dialysis J. 1991;24:1119-24.

11. Kobayashi H, Morita T, Hirata Y, et al. Toxicosis of high-dose methotrexate (HDMTX) for osteosarcoma, cured with treatment by leucovorin (LV) rescue and hemoperfusion — a case report. Cancer and Chemother. 2000;27(3):475-8.

12. Saland JM, Leavey PJ, Bash RO, Hansch E, Arbus GS, Quigley R. Effective removal of methotrexate by high-flux hemodialysis. Pediatr Nephrol. 2002; 17:825-9.

13. Kimura N, Tanaka H, Kawaguchi H, Equchi H, Endo K. Blood purification methods prove to be effective in emergency treatment in a case of delayed excretion of methotrexate. Japan Soc Pharm Health Care Sci. 2006:32:314-9.

14. Sawada M, Fujiwara M, Shimada N, et al. Methotrexate intoxicity treated with hemodialysis and charcoal hemoperfusion in 12-year-old boy. Japan J Ped Nephrol J. 2010;1:74-9.

15. Morozumi I, Inagaki A, Suzuki S, et al. Successful treatment of high-dose methotrexate-induced oliguric acute renal failure by using a combination of hemodialysis filtration and direct hemoperfusion. Cancer and Chemother. 2015:42(5):609-11.

16. Grafft C, Gunderson H, Langman L, Farmer JC, Leung N. High-dose continuous venovenous hemofiltration combined with charcoal hemoperfusion for methotrexate removal. NDT Plus. 2011;4(2):87-9.
17. Bleyer WA. A comprehensive guide to the therapeutic use of methotrexate in bladder cancer, Pharmanual. Pharma Libri Chicago 1983; 51-69.

18. Abelson HT, Fosburg MT, Beardsley GP, et al. Methotrexate-induced renal impairment: clinical studies and rescue from system toxicity with high-dose leucovorin and thymidine. J Clin Oncol. 1983;1(3):208-16.

19. Tanabe $\mathrm{M}$, leiri I, Nagata $\mathrm{N}$, Inoue $\mathrm{K}$, et al. Expression of P-glycoprotein in human placenta; relation to genetic polymorphism of the multidrug resistance (MDR)-1 gene. J Pharmacol Exp Ther. 2001;297:1137-43.

20. Chave KJ, Ryan TJ, Chmura SE, Galivan J. Identification of single nucleotide polymorphisms in the human gamma-glutamyl hydrolase gene and characterization of promoter polymorphisms. Gene. 2003;319:67-175.

21. Chong Q, Wu B, Kager L, et al. A substrate-specific functional polymorphism of human gamma-glutamyl hydrolase alters catalytic activity and methotrexate polyglutamate accumulation in acute lymphoblastic leukemia cells. Pharmacogenetics. 2004;14:557-67.

22. Urano W, Taniguchi A, Yamanaka $\mathrm{H}$, et al. Polymorphisms in the methylenetetrahydrofolate reductase gene were associated with both the efficacy and the toxicity of methotrexate used for the treatment of rheumatoid arthritis, as evidenced by single-locus and haplotype analyses. Pharmacogenetics. 2002;12:183-90.

23. Pinedo HM, Zaharko DS, Bull JM, Chabner BA. The reversal of methotrexate cytotoxicity to mouse bone marrow cells by leucovorin and nucleosides. Cancer Res. 1976;36:4418-24.

24. Perez C, Sutow WW, Wang YM, Herson J. Evaluation of overall toxicity of high-dose methotrexate regimens. Med Pediatr Onco. 1979;16:219-28.

25. Widemann BC, Balis FM, Kempf-Bielack B, et al. High-dose methotrexateinduced nephrotoxicity in patients with osteosarcoma. Cancer. 2004;100: 2222-32.

26. Cavone JL, Yang D, Wang A. Glucarpidase intervention for delayed methotrexate clearance. Annal Pharmacother. 2014;48(7):487-907.

\section{Submit your next manuscript to BioMed Central and we will help you at every step:}

- We accept pre-submission inquiries

- Our selector tool helps you to find the most relevant journal

- We provide round the clock customer support

- Convenient online submission

- Thorough peer review

- Inclusion in PubMed and all major indexing services

- Maximum visibility for your research

Submit your manuscript at www.biomedcentral.com/submit
Biomed Central 